ARTIGOS

\section{POR QUE COMPARTILHAR? UM ESTUDO SOBRE A ECONOMIA COMPARTILHADA NA CIDADE DE FORTALEZA}

\section{RESUMO}

O conceito economia compartilhada aborda práticas comerciais que não possuem a aquisição de um produto, mas, sim, a experiência de sua utilização. Atualmente, existem vários modelos de negócios que estão ancorados nesse conceito, como compartilhamento de bicicletas e carros, espaços de trabalho etc. Este trabalho visa investigar: quais as motivações para a utilização do sistema compartilhado de bicicletas? Além disso, tem como objetivo geral compreender as motivações dos usuários acerca do uso do sistema de bicicletas compartilhadas na cidade de Fortaleza. A pesquisa foi desenvolvida na forma de um estudo quantitativo, com caráter descritivo e amostragem por conveniência. Um questionário com 17 perguntas foi aplicado a uma amostra de 51 usuários do sistema. Os dados coletados foram tabulados e analisados por meio de estatística descritiva. Como principal resultado, observa-se que os usuários possuem três motivações para o uso do sistema: motivação econômica, motivação socioambiental e motivação de bem-estar.

Palavras-chave: Economia compartilhada. Bicicletas compartilhadas. Motivação.

\section{INTRODUÇÃO}

A essência da economia compartilhada versa sobre práticas comerciais que possibilitam o acesso a bens e serviços sem que haja, necessariamente, a aquisição de um produto ou a troca monetária entre os envolvidos (BOTSMAN; ROGERS, 2011). Atualmente, é possível observar a formação de modelos de negócios que possuem a economia compartilhada como base, como o compartilhamento de bicicletas, automóveis, espaços de trabalho, hospedagem, sistema de caronas, entre outros, e muitas dessas práticas são disseminadas por aplicativos on-line que facilitam e viabilizam o empréstimo, a troca e, até mesmo, a revenda desses produtos e serviços.

A economia compartilhada ou consumo colaborativo, como também é conhecido, é um fenômeno recente, ainda está em formação e chega para modificar o paradigma do consumo atual. Esse conceito versa sobre o consumo consciente e o compartilhamento 
de produtos, fazendo que a posse passe a ser menos importante do que a experiência e a sua utilização. Botsman e Rogers (2011) afirmam que a prática da economia compartilhada não é uma tendência de nicho, ela é uma onda socioeconômica que está mudando a forma como as empresas entregam seus produtos e está modificando a forma como os consumidores satisfazem suas necessidades.

É possível observar o fenômeno do consumo desde as civilizações da Antiguidade, seja por questões de sobrevivência alimentar, por necessidade de moradia ou vestimenta, seja por outras questões. Passados vários séculos, o nível de consumo mudou e aumentou, deixando de atender apenas a necessidades básicas dos indivíduos, atendendo, também, a desejos e vontades diversas, como diferenciação por status, individualismos, sentimento de posse, entre outros, os quais são satisfeitos pelo consumo de bens e serviços. $\mathrm{O}$ consumo desenfreado é uma das principais características da sociedade atual, sendo considerado um estilo de vida, não somente um fator econômico (PÁDUA JUNIOR; ALENCASTRO, 2015). Porém, é possível observar que esse modelo tende a não ser sustentável em longo prazo, uma vez que as matérias-primas para a produção dos bens são finitas.

Aliada ao consumo de bens, existe uma tendência de individualização que se acentua à medida que o consumo torna os indivíduos pertencentes a um determinado grupo social, os quais estão, cada vez mais, em voga devido à plataformas digitais de comunicação que permitem a virtualização das comunicações, como afirma Mont (2004).

O consumidor da economia compartilhada é consciente das consequências de seus atos de consumo e passa a atuar dentro da cadeia produtiva de fabricação, fazendo que seu papel não seja visto como o consumidor individual final (como é visto na economia tradicional), mas, sim, como parte integrante de uma coletividade que pode consumir determinado produto sem sua aquisição, o que faz que o compartilhamento amplie o uso do produto para mais pessoas.

Podem-se perceber, nos últimos anos, mudanças significativas no comportamento de compra dos indivíduos (SOLOMON, 2016; SCHOR, 2014, sendo estas decorrentes de inovações tecnológicas, crises econômicas mundiais e preocupações ambientais, que incentivaram práticas colaborativas, em que a propriedade do bem é substituída pela possibilidade de experiência do acesso ao uso do produto. Uma parcela dos consumidores dá sinais de uma maior preocupação com questões sociais e ambientais, demonstrando mais conscientização sobre o reuso de bens (MAURER et al., 2015).

Assim, as motivações de consumo dos consumidores estão mudando. As razões que tendiam para a aquisição de bens e a compra de cada vez mais produtos estão, gradativamente, transformando-se em razões para compartilhamento, em que os indivíduos estão gerando ações coletivas. A posse passa a ser menos importante do que o uso do objeto, e a detenção dos produtos teve sua importância diminuída, embora, agora, a experiência e o uso passem a ter importância maior para o consumidor. É importante ressaltar que, para a manutenção e a expansão do conceito, existem obstáculos comportamentais, como o sentimento de posse e o apego material, refletindo atitudes individualistas, as quais devem ser consideradas.

O conceito de economia compartilhada/ consumo colaborativo está sendo discutido, principalmente, em países europeus e nos Estados Unidos (MAURER et al., 2015); porém, as ações práticas do conceito já podem ser vistas em outros países, inclusive no Brasil, daí a importância de seu estudo. Esse fato torna-se ainda mais evidente na academia, uma vez que é possível encontrar poucos estudos sobre o tema no Brasil (MAURER et al., 2015; VILLANOVA, 2015; PÁDUA JUNIOR; ALENCASTRO, 2015).

Além da pouca literatura nacional sobre o tema, o estudo desse conceito no Brasil enfrenta outro desafio que envolve pontos culturais, como a questão do individualismo e do status que o consumo transfere, que são questões muito importantes para grande parte dos consumidores brasileiros. Como não existe 
sentimento de posse com a economia compartilhada, apenas o uso do objeto enquanto houver necessidade, essa barreira cultural (individualismo, status etc.) deve ser vencida para que o conceito possa ser bem aceito e difundido.

Tendo em vista a rápida expansão do conceito economia compartilhada em outros países e a necessidade de ampliação de seu conhecimento no Brasil, além da importância do seu estudo para a disseminação de novas formas de consumo e do melhor entendimento de como o consumidor se comporta em relação ao uso de bens e serviços e sua posse, a pesquisa que norteia o desenvolvimento deste artigo é: quais as motivações para a utilização do sistema compartilhado de bicicletas?

A partir desse questionamento, tem-se, como objetivo geral, compreender as motivações dos usuários acerca do uso do sistema de bicicletas compartilhadas na cidade de Fortaleza e como objetivos específicos: descrever o perfil do usuário do sistema compartilhado; compreender as motivações que impulsionam as pessoas a serem usuárias do sistema compartilhado e compreender as motivações para a utilização do sistema compartilhado.

\section{REFERENCIAL TEÓRICO}

Esta pesquisa tem como fundamentação teórica dois conceitos atuais e importantes para a teoria administrativa: a economia compartilhada e o comportamento do consumidor (com foco nas motivações dos consumidores) que serão detalhados nesta sessão.

\subsection{ECONOMIA COMPARTILHADA}

A economia compartilhada, também denominada de economia mesh (GANSKY, 2010) ou consumo colaborativo (BOTSMAN; ROGERS, 2011) é uma tendência que se expande por meio de novas organizações, tendo seu foco o compartilhamento de recursos e/ou produtos (GANSKY, 2010).

Para Gansky (2010), economia compartilhada é um sistema socioeconômico constru- ído em torno do compartilhamento de recursos humanos e físicos, o qual inclui a criação, a produção, a distribuição, o comércio e o consumo compartilhado de bens e serviços tanto por pessoas, quanto por organizações. Botsman e Rogers (2011) conceituam a economia compartilhada, ou consumo colaborativo, como um conjunto de práticas comerciais que possibilitam o acesso a bens e serviços, podendo não haver a aquisição de um produto ou troca monetária entre as partes envolvidas. Essas práticas são constituídas por transações como o compartilhamento, empréstimo, aluguel, doação ou trocas (BOTSMAN; ROGERS, 2011). Já para Dubois, Schor e Carfagna (2014), a economia compartilhada é constituída por práticas de connected consumption, isto é, consumo conectado, que enfatiza a reutilização de produtos, eliminando intermediários, levando a conexões face a face que estão redesenhando os modelos de negócio da economia tradicional. Para os autores, o consumo conectado deve ter essencialmente a mediação de uma tecnologia que será responsável posteriormente pelo encontro pessoal.

Para Botsman e Rogers (2011), o desenvolvimento da economia compartilhada deve-se a uma conjunção de fatores sociais, econômicos e tecnológicos. No que tange aos fatores sociais, constata-se uma crescente preocupação com questões relacionadas à sustentabilidade e meio-ambiente. Para Dubois, Schor e Carfagna (2014), também existem questões sociais relacionadas ao desejo dos participantes de fazerem novas conexões sociais. Quanto aos fatores econômicos, a economia compartilhada possibilita a monetização do excesso e da ociosidade dos estoques individuais (BOTSMAN; ROGERS, 2011), fazendo surgir um novo modelo econômico em que as pessoas ficam menos dependentes de empregadores e mais capazes de diversificar as suas fontes de renda (DUBOIS; SCHOR; CARFAGNA, 2014). E, por fim, os fatores tecnológicos proporcionaram a disseminação de redes sociais e a redução dos custos das transações entre pares, conectando diretamente consumidores a produtores e reduzindo 
os custos de intermediação (BOTSMAN; ROGERS, 2011).

As redes sociais, por exemplo, são uma antiga forma de organização da humanidade (CASTELLS, 2013), entretanto, antes da internet, os custos para coordenar transações entre grupos de pessoas eram elevados, tornando o compartilhamento de produtos e serviços restrito às pessoas próximas (BOTSMAN; ROGERS, 2011). Com a redução desses custos, as relações construídas em redes sociais se tornam uma modalidade crescente de produção econômica (BENKLER, 2006). Por meio das redes, os indivíduos, mesmo desconhecidos, conectam-se, realizam trocas, compartilham informações e cooperam entre si, impulsionando a disseminação das plataformas de economia compartilhada (SCHOR, 2014).

Importante observar que o desenvolvimento industrial contribuiu, de forma significativa, para que as sociedades tivessem, à sua disposição, quantidade e variedade cada vez maior de produtos. As empresas passaram a estimular o consumo por meio de estratégias de marketing que incitam desejos, até mesmo, quando as necessidades já estão satisfeitas, o que promove a obsolescência dos produtos, desenvolvendo a cultura de bens descartáveis (DAUGVERNE, 2010). Entretanto, vê-se que esse padrão de consumo parece ser insustentável frente aos recursos naturais disponíveis, uma vez que eles são esgotáveis, o que tem despertado uma consciência maior em torno da sustentabilidade e uma atitude mais crítica em relação aos padrões de consumo tradicionais em determinados segmentos da sociedade atual (PALFREY; GASSER, 2008).

Segundo Botsman e Rogers (2011), os princípios para o funcionamento da economia compartilhada são massa crítica, ou seja, a quantidade de usuários necessária e suficiente para sustentar uma prática econômica; capacidade ociosa; crença no bem comum e confiança entre desconhecidos. Os autores complementam afirmando que nem um princípio é mais importante do que outro, todos estão no mesmo nível, porém, em alguns casos, determinado princípio é fundamental para o sistema funcionar e, em outros casos, ele pode ser menos importante.

Para Schor (2014), as participações nas atividades da economia compartilhada têm, como motivo, os fatores econômicos, ambientais e sociais e variam de acordo com a diversidade das atividades. Algumas pessoas participam, visando aos benefícios econômicos, como economizar dinheiro (BOTSMAN; ROGERS, 2011); algumas conquistando novos amigos (BOTSMAN; ROGERS, 2011); e outras são atraídas pelo modismo ou novidade das plataformas (SCHOR, 2014). Botsman e Rogers (2011) afirmam que a economia compartilhada resgata comportamentos naturais dos seres humanos, como o compartilhamento e a troca, os quais podem ter seu potencial aumentado por meio de interações via Internet.

Cabe aqui esclarecer que pode existir uma lacuna entre a atitude de aderir a economia compartilhada. As pessoas podem até ter uma percepção positiva da economia compartilhada apoiando-a independentemente do produto, mas podem não a aderir, por questões comportamentais, sentimento de posse e apego a bens materiais, como afirma Belk (2014).

No Brasil, é possível observar algumas iniciativas de economia compartilhada, que envolvem o compartilhamento de automóveis, bicicletas, espaços de trabalho, caronas e hospedagem que funcionam através de sites de trocas, plataformas de financiamento e produção coletiva (PORTAL CONSUMO COLABORATIVO, 2016), inclusive o sistema de bicicletas compartilhadas de Fortaleza que será objeto de pesquisa desta tese.

Segundo Botsman e Rogers (2011), as atividades que fazem parte da economia compartilhada podem ser classificadas em três tipos: sistema de serviço e produto, mercado de redistribuição e estilo de vida colaborativo.

O sistema de serviço e produto diz respeito ao pagamento pela utilização de determinado produto, sem sua compra, isto é, paga-se pela utilização e pelo benefício que o produto/ bem oferta. Botsman e Rogers (2011) concei- 
tuam mercado de redistribuição como sendo a reutilização ou a revenda de produtos já utilizados, representando a retomada do escambo (realização de trocas sem a utilização de moeda), agora com uma poderosa ferramenta de comunicação, a Internet, o que viabiliza canais mais eficientes de comunicação e de troca. Esse sistema encoraja o reuso e a redistribuição de itens. É baseado no sistema sustentável de comércio, utilizando os 5R's: redução, reciclagem, reuso, reparo e redistribuição (ORNELLAS, 2013).

$\mathrm{O}$ último tipo definido pelos autores, estilo de vida colaborativa, caracteriza-se pela reunião de pessoas com interesses semelhantes que estão dispostas a realizar trocas menos tangíveis, como trocas de tempo e habilidades. Requer alto nível de confiança entre os participantes, uma vez que não diz espeito a trocas de produtos físicos, mas sim uma interação social e física (ORNELLAS, 2013).

O Quadro 1 apresenta exemplos de atividades na economia compartilhada, já existentes em vários países, que se encaixam na classificação dos autores.

\begin{tabular}{|c|c|}
\hline Tipo & Exemplo de atividades \\
\hline \multirow{7}{*}{$\begin{array}{c}\text { Sistemas de serviços de } \\
\text { produtos }\end{array}$} & Bike Rio (compartilhamento de bicicletas) \\
\hline & B-cycle - EUA (compartilhamento de bicicletas) \\
\hline & Zascar (compartilhamento de automóveis) \\
\hline & Zipcar - EUA, Street Car - UK (car sharing- B2P) \\
\hline & RelayRides - EUA (compartilhamento de automóveis) \\
\hline & Netflix (compartilhamento de filmes) \\
\hline & Buscalá (aluguel de produtos diversos) \\
\hline \multirow{6}{*}{$\begin{array}{l}\text { Mercados de } \\
\text { redistribuição }\end{array}$} & TemAçucar (empréstimos e doação entre vizinhos) \\
\hline & Tomaladaca (troca de produtos e serviços) \\
\hline & Xcambo (troca de produtos) \\
\hline & Trocandolivros (troca de livros) \\
\hline & Projeto Gaveta (troca de roupas) \\
\hline & Trocacasa (troca de casas entre viajantes pelo mundo) \\
\hline \multirow{11}{*}{ Estilo de vida colaborativo } & The HUB (coworking) \\
\hline & Nós (coworking) \\
\hline & Couchsurfing (compartilhamento de hospedagem) \\
\hline & Airbnb (compartilhamento de hospedagem) \\
\hline & Zimride - EUA (sistema de caronas) \\
\hline & Wegocaronas, ponga.mobi, Tripda (sistema de caronas) \\
\hline & KickStarter - EUA (crowdfunding) \\
\hline & Catarse (crowdfunding) \\
\hline & Wikipedia (crowdsourcing) \\
\hline & Bliive (troca de serviço - banco de tempo) \\
\hline & Timerepublik (troca de serviço - banco de tempo) \\
\hline
\end{tabular}

Quadro 1 - Exemplos de atividades existentes na economia compartilhada

Fonte: adaptado de Villanova (2015).

Para Ornellas (2013), a sustentabilidade é uma das consequências da economia compartilhada uma vez que pode reduzir emissão de gases poluentes com a utilização de menos carros, diminuir, potencialmente, a produção de lixo, pois, com o conserto de produtos, eles passam a ser reutilizados e não se tornam lixo. Pode ocorrer distribuição de renda à medida que empregos relacionados a esse tipo de economia são criados (exemplo: oficinas de conserto de produtos, escritórios de compartilhamento e aluguel de bens, entre outros). Porém, pode-se destacar que o fator sustentabilidade pode não ser a principal motivação dos indivíduos buscarem serviços da economia compartilhada, como afirmam Arruda et al. (2016) que apontam que os principais mo- 
tivos que levaram os indivíduos a escolherem o uso de bicicletas compartilhadas foi economia de custos e de tempo.

Por fim, é importante salientar, também, que não se trata de propagar a substituição dos modelos de consumo atuais ao modelo proposto pela economia compartilhada, mas, sim, apresentar uma alternativa viável para a utilização de bens e mercadorias sem a necessidade de posse (MAURER et al., 2015).

\subsection{COMPORTAMENTO DO CONSU- MIDOR}

Solomon (2016) afirma que o comportamento do consumidor é o estudo dos processos envolvidos quando um indivíduo ou um grupo de pessoas selecionam, compram, usam ou descartam um determinado produto, serviço, ideia ou experiências para satisfazerem suas mais diversas necessidades e desejos. O processo estudado dentro do comportamento do consumidor envolve um ator e uma ação, isto é, envolve o consumidor e a ação de troca. A troca pode ser considerada como uma transação em que duas organizações ou pessoas dão e recebem algo de valor e envolve todo o processo de escolhas e decisão de compra, sendo que o consumidor é a pessoa que identifica uma necessidade ou desejo, realiza a compra, utiliza o produto e depois o descarta. Em muitos casos, mais pessoas podem estar envolvidas no processo de decisão de compra, assumindo papéis de influenciador, decisor, comprador e usuário (SOLOMON, 2016). O estudo do comportamento do consumidor teve origem nas teorias clássicas econômicas, e seu objeto de estudo é ação de escolha que o indivíduo faz a partir do momento que ele decide consumir algo (PORTO, 2010).

Já para Hawkins, Mothersbaugh e Best (2007), o comportamento do consumidor pode ser entendido como um estudo de como os indivíduos, os grupos ou as organizações selecionam, obtêm e usam os serviços e produtos ou experiências e ideias, visando satisfazer desejos e necessidades. Os autores complementam que, além disso, o comportamento do consumi- dor visa estudar o impacto que esses processos de decisão de compra possuem sobre o próprio consumidor e a sociedade de forma geral.

Limeira (2008) complementa, afirmando que a teoria tradicional sobre comportamento do consumidor define o comportamento de consumo como conjunto de reações ou respostas individuais a determinados estímulos que podem advir de fatores sociais, ambientais, situacionais, além de estímulos causados por exposição a ações de marketing.

Algumas variáveis individuais influenciam o comportamento de compra do consumidor, devendo ser consideradas em qualquer estudo sobre esse tema. São elas: percepção, aprendizagem e memória, motivação e valores, personalidade e estilo de vida, atitudes e persuasão (SOLOMON, 2016).

Crocco et al. (2013) afirmam que existem dois grupos de variáveis que podem influenciar o comportamento do consumidor, além da atividade de marketing empresarial que também é responsável por essa influência. O primeiro grupo é formado pelas variáveis sociológicas e psicossociológicas, compostas por questões como influência da família e do grupo, classes sociais, cultura etc., e as variáveis individuais, compostas por questões demográficas, aprendizado, motivação, atitudes, personalidade, estilo de vida etc.

Para esta pesquisa, a variável que influencia o comportamento do consumidor que será estudada é a motivação do consumidor, isto é, o que move o consumidor e determinado serviço/ produto. Solomon (2016) afirma que motivação é um processo que faz que os indivíduos se comportem de uma determinada maneira, ocorrendo quando uma necessidade é apresentada. Penha et al. (2013) afirmam que o conhecimento das motivações dos consumidores em relação ao consumo de bens e serviços é importante uma vez que ajuda a organização a identificar possíveis rejeições aos produtos/serviços ofertados.

Pesquisas sobre o comportamento do consumidor e sobre o mercado utilizam-se de medidas motivacionais e de atitudes para obter seus resultados, mas deve-se considerar que a atitude não é um fenômeno observável, ela 
deve ser inferida a partir dos comportamentos dos indivíduos (PORTO, 2010). Apesar do desafio que é medir a atitude, a estrutura conceitual desse constructo é consenso entre os teóricos, sendo ele composto por três componentes: cognitivo, afetivo e conativo.

A atitude cognitiva envolve os conhecimentos e as crenças sobre um determinado assunto, produto ou serviço. Porto (2010) afirma que os modelos e as teorias que possuem ênfase no componente cognitivo declaram que o indivíduo aprende a consumir influenciado pelos pais, grupos sociais ligados a ele e, até mesmo, pela mídia, e esse processo ocorre durante toda a vida do indivíduo, uma vez que as informações são adquiridas e acumuladas durante essas interações sociais, sejam elas mediadas pelos meios de comunicação ou não.

O segundo componente da atitude é o afetivo, que faz referência aos sentimentos sobre determinado objeto ou pessoa. Aqui o que importa é o julgamento afetivo, o gostar ou não gostar de determinado produto (PORTO, 2010). Por fim, o último componente é a atitude conativa, que se refere às tendências de ação ou aos comportamentos em relação a um determinado objeto (CROCCO et al., 2013).

É importante salientar que o estudo do comportamento do consumidor envolve áreas interdisciplinares, como psicologia, economia, sociologia, antropologia, história entre outras áreas. Atualmente, o aporte conceitual que compõem o estudo sobre o comportamento do consumidor são oriundos dessas áreas do saber, mas estão inseridos no marketing, criando o que Pinheiro et al. (2011) afirmam ser um "tapete conceitual" para a formulação de novos estudos.

Deve-se considerar também, neste estudo, o fator internet que se tornou uma influência significativa na decisão de compra do consumidor, ampliando seu poder de compra, uma vez que as lojas, atualmente, on-line estão abertas 24 horas por dia, sete dias por semana. E não apenas isso, a internet permite que consumidores troquem informações sobre suas experiências e se aproximem dos grupos que compartilham do mesmo desejo de consumo (SOLOMON, 2016).

\section{METODOLOGIA}

A pesquisa foi desenvolvida na forma de um estudo de natureza quantitativa. A pesquisa quantitativa, como afirmam Richardson et al. (2012) caracteriza-se pelo emprego de métodos quantificadores, tanto na coleta, quanto no tratamento dos dados, uma vez que o tratamento se dá por meio de técnicas estatísticas que podem ser mais simples (percentual, média, desvio-padrão, entre outros) até as mais complexas (coeficiente de correlação, análise de regressão etc.). Além disso, o autor afirma que o método quantitativo possui a intenção de garantir a precisão dos resultados, evitando distorções de análise e de interpretação, permitindo, também, a generalização dos resultados, caso o estudo tenha utilizado uma amostra probabilística.

Quanto aos objetivos, esta pesquisa possui teor descritivo (COLLIS; RUSSEY, 2005; SAMPIERI; COLLADO; LUCIO, 2013). O estudo é assim classificado, uma vez que possui, como finalidade, identificar e obter informações sobre as características de um determinado problema ou questão, isto é, "[...] descreve o comportamento dos fenômenos" (COLLIS; HUSSEY, 2005, p. 24), na tentativa de compreendê-los de forma mais clara. Os estudos descritivos descrevem, medem e avaliam dados referentes a vários aspectos do fenômeno pesquisado, apresentando situações e acontecimentos com o intuito de descrever como eles se manifestam (SAMPIERI; COLLADO; LUCIO, 2013). Segundo Gil (2002), pesquisas descritivas são bastante utilizadas por pesquisadores sociais que visam pesquisar a atuação práticas dos conceitos apresentados.

Caracteriza-se, também, quanto aos procedimentos, como uma pesquisa de campo, isto é, a pesquisa será realizada no ambiente natural em que ocorre o fato estudado, não envolvendo experimentação em laboratórios ou em ambientes estranhos ao natural (PÁDUA, 2004).

Esta pesquisa teve como objeto o Sistema de Bicicletas Públicas - Bicicletar (compartilhamento de bicicletas), um projeto da Prefeitura de Fortaleza, operacionalizado pela 
empresa Serttel e com apoio da Unimed Fortaleza. O sistema foi implantado na cidade de Fortaleza, no final de 2014, e visa oferecer uma opção de transporte sustentável e não poluente. $\mathrm{O}$ aluguel de bicicletas funciona de duas formas: se o interessado for possuidor do cartão Bilhete Único, ele terá direito ao uso da bicicleta sem nenhum acréscimo por até 1 hora por dia. Após esse período, serão debitados $\mathrm{R} \$$ 5,00 no Bilhete Único. Caso o interessado não possua o cartão Bilhete Único, ele deve fazer um cadastro no aplicativo do sistema, escolher a forma de aquisição de "passes" que podem ser Passe Diário, no valor de R\$ 5,00, válido por 24 horas; Passe Mensal, no valor de R\$ 10,00 e Passe Anual, no valor de R $\$ 60,00$. Em cada uma das modalidades, a bicicleta pode ser usada por uma hora após a retirada da estação. Não existe limite de empréstimo de bicicletas, porém o usuário deve esperar 15 minutos entre cada retirada. Atualmente, o sistema conta com 80 estações distribuídas entre os diversos bairros de Fortaleza, contando com um total de 690 bicicletas aptas a ser usadas, segundo informações da Secretaria Municipal de Conservação e Serviços Públicos de Fortaleza. O usuário pode retirar a bicicleta em qualquer uma das estações, realizar o percurso que desejar e, ao final, ele deve depositar a bicicleta em qualquer uma das estações, não necessariamente a mesma estação de onde a bicicleta foi retirada.

A amostra foi composta por 51 usuários do sistema que se voluntariaram a participar da pesquisa por meio de questionário estruturado e disponibilizado via internet, por meio da ferramenta Google Forms, entre os meses de junho e agosto de 2017. Assim, o processo de amostragem deste estudo configura-se por conveniência. Nique e Ladeira (2017) afirmam que, nesse tipo de amostragem, o pesquisador seleciona as pessoas que irão participar de forma que lhe seja mais conveniente, isto é, estão mais acessíveis ao pesquisador. Em consequência desse tipo de amostragem, não se pode generalizar resultados, e eles não podem ser usados para inferir características de toda uma população.

O questionário contém 17 perguntas que tinham o intuito de realizar uma caracterização do perfil sociodemográfico e identificar as seguintes questões: há quanto tempo o respondente é usuário do sistema de bicicletas compartilhadas?; quais as estações que são mais utilizadas?; quais as motivações que levam os usuários a usarem as bicicletas compartilhadas?; quais os principais problemas encontrados pelos usuários na utilização das bicicletas?; quais são os fatores positivos e negativos na utilização das bicicletas?. Deve-se identificar se o usuário pretende comprar uma bicicleta ou se continuará a utilizar o sistema de bicicletas compartilhadas.

A análise dos dados foi realizada por meio do programa Microsoft Excel, em que foram aplicadas técnicas de estatística descritiva que têm como finalidade descrever simetrias e resumir dados (SILVESTRE, 2007).

\section{ANÁLISE DOS RESULTADOS}

Inicialmente, a pesquisa se propôs a identificar qual o perfil dos usuários do sistema de bicicletas compartilhadas. Com base nos dados coletados, observa-se que $55 \%$ dos respondentes estão entre a faixa etária de 25 a 34 anos, e $20 \%$ dos respondentes têm até 24 anos, conforme pode ser visto no gráfico 1. Esse achado afasta-se um pouco do encontrado no artigo de Arruda et al. (2016), uma vez que, na pesquisa realizada pelos autores, a maioria $(51,7 \%)$ dos respondentes tinha até 25 anos.

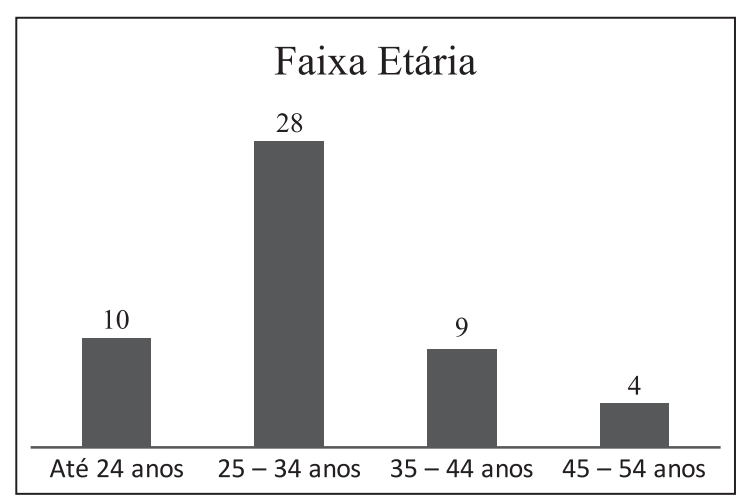

Gráfico 1 - Faixa etária

Fonte: dados da pesquisa (2017). 
Foi questionada, também, a escolaridade dos respondentes, em que 35\% informaram possuir ensino superior incompleto/cursando; $20 \%$ informaram possuir pós-graduação, seja ela especialização, mestrado ou doutorado, e $16 \%$ informaram possuir ensino superior completo, conforme pode ser visualizado no gráfico 2. Esse resultado corrobora o encontrado por Arruda et al. (2016), em que $84 \%$ dos seus pesquisados apresentaram ensino superior completo ou em andamento. Além disso, o usuário do sistema de bicicletas compartilhadas possui várias ocupações, como publicitário, jornalista, professor, administrador, estudante, bancário, contador, dentre outras.

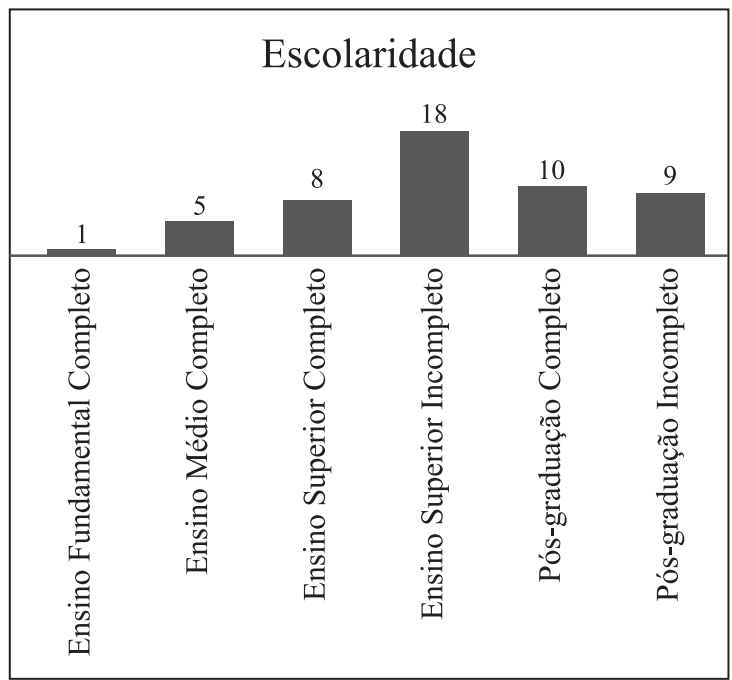

Gráfico 2 - Escolaridade

Fonte: dados da pesquisa (2017).

Sobre a renda dos respondentes, $49 \%$ (25 indivíduos) informaram que possuem renda de até 2 salários mínimos, seguidos de 25\% (13 indivíduos) que afirmaram ganhar entre 2 a 4 salários-mínimos. Esse achado, também, distancia-se do encontrado por Arruda (2016) em que a ampla maioria, $81,3 \%$ possuíam renda de até 4 salários-mínimos.

A partir da caracterização do perfil do consumidor, as perguntas visavam identificar e compreender quais as motivações e as atitudes dos usuários acerca do uso das bicicletas compartilhadas. Quando os participantes fo- ram questionados sobre o tempo que usavam o sistema de bicicletas compartilhadas, $49 \%$ (25 indivíduos) apontaram que utilizam desde a inauguração, isto é, utilizam desde o final de 2014, conforme pode ser visualizado no gráfico 3. Pode-se supor que o uso das bicicletas compartilhadas para esses respondentes não se configura como modismo, isto é, o uso do bem só porque ele está na moda.

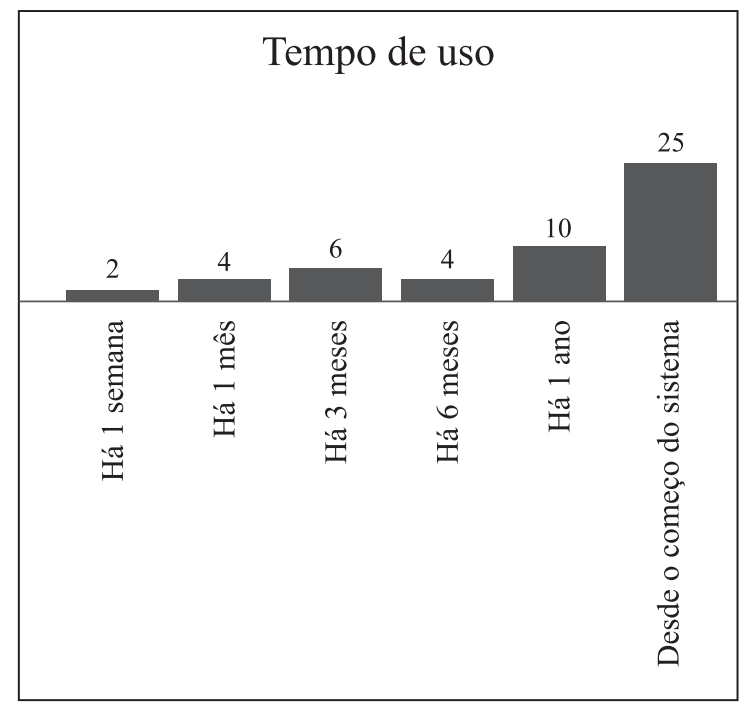

Gráfico 3 - Tempo de uso do sistema

Fonte: dados da pesquisa (2017).

Quando os respondentes foram questionados sobre a periodicidade de uso das bicicletas compartilhadas, $29 \%$ informaram que as utilizam uma vez por mês, seguida de 3 a 4 vezes por semana (20\%), conforme pode ser visualizado no gráfico 4 . Os nove respondentes que apontaram a opção "outros” informaram que a utilização do sistema estava dando-se de forma esporádica, sem uma periodicidade fixa. 


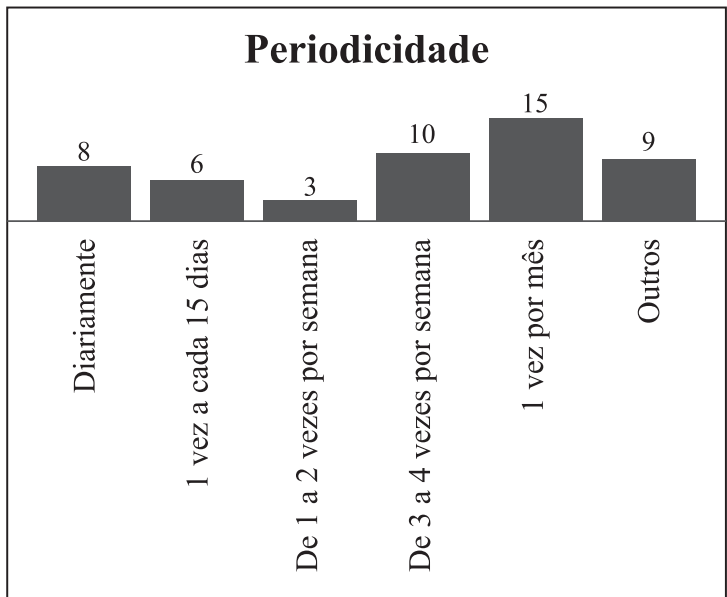

Gráfico 4 - Periodicidade de uso

Fonte: dados da pesquisa (2017).

Quando os respondentes foram questionados sobre a forma utilizada para a habilitação da retirada da bicicleta, 75\% (38) dos respondentes informaram que utilizam o bilhete único, e $25 \%$ (13) afirmaram que utilizavam o aplicativo de celular bicicletar. Esse achado se afasta do que Botsman e Rogers (2011) afirmam, uma vez que, para os autores, o crescente uso da internet deu aos serviços da economia compartilhada mais possibilidade de crescimento e foram, até mesmo, impulsionados pelo ela. E o que se percebe com o achado desta pesquisa é que a maioria não usa o aplicativo de celular, preferindo o cartão disponibilizado pela prefeitura. Além disso, 47\% (24) dos respondentes informaram que o tempo médio de duração de cada viagem, utilizando a bicicleta compartilhada, é entre 30 minutos e 1 hora, seguido de $31 \%$ (16), os quais afirmaram que utilizam as bicicletas entre 15 e 30 minutos.

Uma ampla maioria dos respondentes informou que acha o processo de aluguel de bicicletas simples, 92\% (47 respondentes); porém, apesar de o processo ser simples, $57 \%$ (29 respondentes) informaram que nem sempre encontram bicicletas disponíveis nas estações onde mais utilizam. Além disso, apenas seis pessoas afirmaram que nunca tiveram problemas com a utilização das bicicletas. Entre os $88,2 \%$ (45 respondentes) que informaram terem tido problemas de uso (poderiam informar mais de um problema), 72,5\% (37) deles afir- maram que as bicicletas estavam com defeito; seguidos de 54,9\% (28) que afirmaram problemas de liberação de bicicleta do aplicativo ou do bilhete único.

Quando os respondentes foram questionados sobre os motivos da utilização do sistema de bicicletas compartilhadas (poderiam apontar mais de uma justificativa), 72,5\% (37) respondentes afirmaram que "Gosto de praticar exercício físico"; 31,4\% (16) indivíduos responderam "Como meu trajeto é curto, é melhor me deslocar de bicicleta do que de ônibus/carro"; 27,5\% (14) respondentes também afirmaram "Preocupo-me com o nível de poluição liberado pelos carros/ ônibus"; outras justificativas foram apresentadas no campo aberto, como: "Utilizo para driblar engarrafamentos"; "Utilizo, pois os ônibus são muito lotados"; "Quero contribuir para um trânsito com cada vez menos carros"; também foram apresentadas, porém, apenas uma vez cada. Esse achado se aproxima com o que afirmam Botsman e Rogers (2011) na medida em que preocupações no que diz respeito à sustentabilidade ambiental e meio ambiente são frequentes aos usuários dos serviços da economia compartilhada.

Observou-se, ainda, que as estações onde ocorrem o maior número de retiradas de bicicletas são: estação 23 - Unimed, seguida da estação 1 - Praça Luiza Távora e da estação 32 - Praça da Gentilândia. A estação da Unimed e a Praça Luiza Távora são estações situadas no bairro Aldeota, bairro rico da capital cearense que possui população de 42.361 habitantes, sendo a maioria mulher (24.381), com renda média de $\mathrm{R} \$ 2.670,6$, Índice de Desenvolvimento Humano (IDH) de 0,86, segundo dados da Prefeitura de Fortaleza. Já a terceira estação com maior retirada de bicicletas está situada no bairro Gentilândia, conhecido como bairro jovem, pois possui o campus da Universidade Federal do Ceará e do Instituto Federal de Ciência e Tecnologia. Ainda segundo informações do site da Prefeitura de Fortaleza, o bairro possui 3.969 habitantes, sendo 2.280 mulheres, com renda média de R $\$ 1.312,09$ e IDH de 0,62.

Por fim, 52,9\% (27) dos respondentes afirmaram que pretendem comprar uma bici- 
cleta para seu deslocamento. Esse achado corrobora o que Belk (2014) afirma, na medida em que as pessoas podem até conhecer e ter uma atitude positiva em relação aos serviços da economia compartilhada (como apontado nesta pesquisa), mas, por questões comportamentais, como sentimento de posse e apego aos bens materiais, os indivíduos ainda preferem comprar seus bens e ter a posse deles a usar os serviços/produtos compartilhados.

\section{CONSIDERAÇÕES FINAIS}

Esta pesquisa teve como objetivo compreender as motivações dos usuários acerca do uso do sistema de bicicletas compartilhadas na cidade de Fortaleza. Para que esse objetivo fosse alcançado, elaboraram-se dois objetivos específicos: descrever o perfil do usuário do sistema compartilhado e compreender as motivações para a utilização do sistema compartilhado.

Tendo em vista responder ao primeiro objetivo específico (descrever o perfil do usuário do sistema compartilhado), o consumidor do sistema de bicicletas compartilhadas trabalha nas mais variadas profissões (professor, publicitário, jornalista, contador, técnico de TI, engenheiro de software, entre outras profissões), possui entre 25 e 34 anos, tem o ensino superior incompleto/cursando e possuem renda de até dois salários mínimos.

Ao responder ao segundo objetivo específico (compreender as motivações para a utilização do sistema compartilhado), pôde-se observar variadas motivações dos indivíduos para a utilização das bicicletas compartilhadas, entre elas: motivação econômica, uma vez que a ampla maioria utiliza o bilhete único, economizando na retirada da bicicleta; além disso, muitos respondentes afirmaram que as estações ficam próximas às suas casas e ao trabalho, compensando, financeiramente, a utilização da bicicleta e o não uso de carro/ônibus; motivação socioambiental, contribuir para a redução da poluição urbana e para a redução do trânsito diário; motivação de bem-estar, uma vez que o uso das bicicletas, para muitos respondentes, é com a finalidade de praticar atividade física ao ar livre.
Acredita-se que esta pesquisa oferece informações pertinentes sobre a economia compartilhada, o uso do sistema de bicicletas compartilhadas na cidade de Fortaleza, ampliando o entendimento do conceito e trazendo um tema em franca investigação para o âmbito regional/ local. Pode-se apontar, como limitação deste estudo, a amostra reduzida, ocasionando a não possibilidade de generalização dos resultados, o que seria solucionado a partir da utilização de uma amostra probabilística, além da não utilização de métodos estatísticos para a análise dos dados (correlação ou análise fatorial).

Esta pesquisa sugere a continuidade da investigação do tema economia compartilhada e de todas as suas ferramentas e bens, além do estudo de como o comportamento do consumidor vem-se alterando com base nesses novos modelos de negócios que estão surgindo, na tentativa de consolidar o consumo mais sustentável em meio a uma sociedade que ainda é tão baseada no capitalismo.

Por fim, como sugestão de estudos a serem desenvolvidos no futuro, aponta-se a realização de pesquisas sobre o sistema de carros compartilhados, também disponibilizados pela Prefeitura de Fortaleza, a fim de compreender as motivações de uso desse tipo de bem na da economia compartilhada.

\section{WHY SHARE? A STUDY ON SHARED ECONOMICS IN THE CITY OF FORTALEZA}

\section{ABSTRACT}

The concept of shared economy addresses commercial practices that do not have the acquisition of a product, but rather the experience of its use. Currently, there are several business models that are anchored in this concept, such as sharing bicycles and cars, workspaces, etc. This work aims to investigate: what are the motivations for using the shared bicycle system? In addition, its general objective is to understand the motivations of users about the use of the shared bicycle system in the city of Fortale- 
za. The research was developed in the form of a quantitative study, with descriptive character and sampling for convenience. A questionnaire with 17 questions was applied to a sample of 51 users of the system. The data collected were tabulated and analyzed through descriptive statistics. As a main result, it is observed that users have three motivations for the use of the system: economic motivation, socio-environmental motivation and well-being motivation.

Keywords: Shared economy. Shared bicycles. Motivation.

\section{¿POR QUÉ COMPARTIR? UN ESTUDIO SOBRE LA ECONOMÍA COMPARTIDA EN LA CIUDAD DE FORTALEZA}

\section{RESUMEN}

El concepto economía compartida aborda prácticas comerciales que no poseen adquisición de un producto, pero sí la experiencia de su utilización. Actualmente, existen diversos modelos de negocios que están fundamentados en este concepto, tales como compartimiento de bicicletas y coches, espacios de trabajo y otros más. Esta pesquisa tiene por finalidad investigar: ¿cuáles las motivaciones para la utilización del sistema compartimentado de bicicletas? Además, tiene como objetivo general, comprender las motivaciones de los usuarios acerca del uso de los sistemas de bicicletas compartimentadas en la ciudad de Fortaleza. La investigación fue desarrollada a través de un estudio cuantitativo, con carácter descriptivo y muestra por conveniencia. Un cuestionario con 17 preguntas fue aplicado a una muestra de 51 usuarios del sistema. Los datos colectados fueron tabulados y analizados a través de la estadística descriptiva. Como principal resultado, observase que los usuarios poseen tres motivaciones para el uso del sistema: motivación económica, motivación socio ambiental y motivación de bienestar.

Palabras-clave: Economía compartimentada. Bicicletas compartimentadas; Motivación.

\section{REFERÊNCIAS}

ARRUDA, Hanna Rocha de et al. Consumo colaborativo e valores pessoais: o caso da bicicleta compartilhada. ReMark - Revista Brasileira de Marketing, v. 15, n. 5, p. 683-398, out./dez. 2016.

BELK, R. You are what you can access: Sharing and collaborative consumption online. Journal of Business Research, v. 67, p. 15951600, 2014.

BENKLER, Y. The wealth of networks: How social production transforms markets and freedom. New Haven: Yale University Press, 2006.

BOTSMAN, R.; ROGERS, R. O que é meu é seu: Como o consumo coletivo está mudando o nosso mundo. Porto Alegre: Bookman, 2011. CASTELlS, M. A sociedade em rede. 6. ed. São Paulo: Paz e Terra, 2013.

COLLIS, Jill; HUSSEY, Roger. Pesquisa em administração: um guia prático para alunos de graduação e pós-graduação. 2. ed. Porto Alegre: Bookman, 2005.

CROCCO, Luciano et al. Fundamentos de marketing: conceitos básicos. São Paulo: Saraiva, 2013.

DAUGVERNE, P. The problem of consumption. Global Environmental Politics, v. 10, n. 2, p. 1-10, 2010.

DUBOIS, E.; SCHOR, J.; CARFAGNA, L. Connected Consumption: a sharing economy takes hold. Rotman Management Spring, p. 50-57, 2014.

FORTALEZA. Prefeitura de Fortaleza. Fortaleza em mapas. Disponível em: $<$ http://mapas.fortaleza.ce.gov.br>. Acesso em: 16 nov. 2018.

GANSKY, L. The mesh: why the future of business is sharing. New York: Portfolio Penguin, 2010. 
GIL, Antônio Carlos. Como elaborar projetos de pesquisa. 4. ed. São Paulo: Atlas, 2002.

HAWKINS, Del I.; MOTHERSBAUGH, David L.; BEST, Roger J. Comportamento do consumidor: construindo a estratégia de marketing. Rio de Janeiro: Elsevier, 2007.

LIMEIRA, Tania Maria Vidigal. Comportamento do consumidor brasileiro. São Paulo: Saraiva, 2008

MAURER, Angela Maria et al. Yes, We also can! O desenvolvimento de iniciativas de consumo colaborativo no Brasil. BASE - Revista de Administração e Contabilidade da Unisinos, v. 12, n. 1, p. 68-80, jan./mar. 2015.

MONT, Oksana. Institutionalization of sustainable consumption patterns based on shared use. Ecological Economics, v. 50, p. 135-153, 2004.

NIQUE, Walter; LADEIRA, Wagner. Como fazer pesquisa de marketing: um guia prático para a realidade brasileira. São Paulo: Atlas, 2017.

ORNELLAS, Regina. Impactos do consume colaborativo de veículos elétricos na cidade de São Paulo. Future Studies Research Jounal, v. 5, n. 1, p. 33-62, jan./jun. 2013.

PADUA, Elisabete Matallo Marchesini de. Metodologia da pesquisa: abordagem teórico-prática. 10. ed. Campinas: Papirus, 2004.

PÁDUA JÚNIOR, Fábio Pimenta de; ALENCASTRO, Mario Sergio Cunha. Desafios do consume colaborativo. In: ENCONTRO DA ASSOCIAÇÃO NACIONAL DE PÓS-GRADUAÇÃO E PESQUISA EM AMBIENTE E SOCIEDADE, 7., 2015, Brasília. Anais... Brasília: UNB, 2015.

PALFREY, J.; GASSER, U. Born digital understanding the first generation of digital natives. New York: Basic Books, 2008.
PENHA; Emanuel Dheison dos Santos et al. A influência da responsabilidade social empresarial sobre a atitude do consumidor: uma investigação no setor bancário de Fortaleza. In: ENCONTRO DE ESTUDOS EM ESTRATÉGIA, 6., 2013, Bento Gonçalves. Anais... Rio Grande do Sul: ANPAD, 2013.

PINHEIRO, Roberto Meireles et al. Comportamento do consumidor. Rio de Janeiro: Editora FGV, 2011.

PORTAL CONSUMO COLABORATIVO. Brasil, 2016. Disponível em:

$<$ http://www.consumocolaborativo.cc $>$. Acesso em: 3 set. 2016.

PORTO, Rafael Barreiros. Atitude do consumidor: estrutura dos modelos teóricos. Remark Revista Brasileira de Marketing, v. 9, n.2, p. 41-58, maio/ago. 2010.

RICHARDSON, Roberto Jarry et al. Pesquisa social: métodos e técnicas. São Paulo: Atlas, 2012.

SAMPIERI, R. H.; COLLADO, C. F.; LUCIO, P. B. Metodologia de pesquisa. 3. ed. São Paulo: McGraw-Hill, 2013.

SCHOR, J. Debating the sharing economy. Great Transition Iniciative, 2014. Disponível em: $<$ http://greattransition.org/publication/debating-the-sharing-economy>. Acesso em: 19 set. 2017.

SILVESTRE, Antônio Luís. Análise de dados e estatística descritiva. São Paulo: Escolar Editora, 2007.

SOLOMON, Michael R. O comportamento do consumidor comprando, possuindo e sendo. 7 . ed. Porto Alegre: Bookman, 2016.

VILLANOVA, Ana Luisa Ilha. Modelos de negócio na economia compartilhada: uma investigação multi-caso. Dissertação (Mestrado) - Fundação Getúlio Vargas - Escola Brasileira de Administração Pública e de Empresas, Rio de Janeiro, 2015. 